\title{
Legal Gender Recognition in Portugal: A Path to Self-Determination
}

\author{
Carla Moleiro and Nuno Pinto ${ }^{1}$
}

\section{Abstract}

This paper presents research on the enforcement and impact of the first legal gender recognition legislation in Portugal (Law no.7/2011). The study describes how the administrative process created by the law functioned during its initial 5-year period, and identifies challenges and processes of resistance to this legal innovation. Simultaneously, it seeks to assess the impact of the law on the social and psychological well-being of trans people, including in their access to vital spheres of social life such as education and employment. The research employs a mixed-methods approach and a multi-informant methodology: an online questionnaire was completed by 68 trans and non-binary people, and semi-structured in-depth interviews were carried out with various selected stakeholders: representatives of trans and LGBTIQ+ organisations $(n=5)$, health professionals identified as experts in the topic and as gatekeepers in legal gender recognition processes $(n=12)$, and trans people $(n=6)$. Results show, on the one hand, the significant positive impact that legal gender recognition has on the psychological well-being and social welfare of the participants. On the other hand, results also show several challenges and forms of resistance to the implementation of the law, in particular those challenges resulting from the fact that legal gender recognition depended on a clinical diagnosis and the provision of a clinical report.

\section{Keywords}

Portugal; Legal gender recognition; Psychological and social impact; Trans and nonbinary; Resistance to legal innovation

\section{Biographies}

\footnotetext{
${ }^{1}$ Carla Moleiro, Associate Professor and Researcher, CIS-IUL/ISCTE-Instituto Universitário de Lisboa. Email: carla.moleiro@iscte-iul.pt

Nuno Pinto, Researcher,CIS-IUL/ISCTE-Instituto Universitário de Lisboa. Email: nunogpinto@gmail.com

Citation Format: Moleiro, C and Pinto, N, 'Legal Gender Recognition in Portugal: A Path to SelfDetermination' (2020) 1 International Journal of Gender, Sexuality and Law 218
} 
Carla Moleiro is an Associate Professor in the Department of Social and Organizational Psychology of ISCTE - Lisbon University Institute. She holds a PhD in Clinical Psychology from the University of California, Santa Barbara, having initially trained in Clinical Psychology at the University of Lisbon and as a psychotherapist at the Portuguese Association of Cognitive-Behavioral and Integrative Psychotherapies. Currently she is a researcher at the Center for Psychological Research and Social Intervention (CIS), working on mental health and diversity.

Nuno Pinto holds a PhD in Psychology from ISCTE-Lisbon University Institute. His doctoral project was focused on the study of developmental processes and identities of trans people, and on the study of social representations on transsexuality and gender. He also holds a post-graduate degree in Political Psychology by the University of Oporto. He has a special interest in the study of LGBTIQ+ health, as well as consulting and training of professionals. 


\section{Introduction $^{2}$}

The trans and non-binary population is comprised of people who identify with a gender that is not congruent with the sex assigned to them at birth. These communities tend to be targeted with particularly strong forms of stigma and discrimination, including institutional, social, psychological and physical harassment and violence. International research clearly shows that, for trans and non-binary people, discrimination and stigma have been and remain a reality in most crucial social spheres: within the family and other significant relationships; in schools; in access to employment and in the workplace; in the public space; and in the access to goods and services - including to gender affirming health care (e.g. European Commission, 2012; Hines, 2007; Kenagy, 2005; Lombardi, Wilchins, Priesing and Malouf, 2001; Pinto and Moleiro, 2015; Nuttbrock, Hwahng, Bockting et al., 2010; Rotondi, Bauer, Scanlon et al., 2011; Pitts, Couch, Mulcare et al., 2009).

Findings from the European Union Agency for Fundamental Rights (FRA) report on the situation of trans people in the European Union (FRA, 2014)) show that "the level of perceived discrimination EU trans respondents report is alarming" (FRA, 2014, p. 21). The findings refer to the year preceding the survey, within which more than half of all participants (54\%) felt personally discriminated against or harassed due to other's perception of them as trans. Young trans people, people not in paid work or from a low social income class, were more likely to feel discriminated against. The U.S. National Centre for Transgender Equality describes "disturbing patterns of mistreatment and discrimination and startling disparities between transgender people in the survey and the U.S. population when it comes to the most basic elements of life" (James, Herman, Rankin et al., 2016, p.4), such as finding a job, having a place to live, accessing medical care, and enjoying the support of family and community.

Unsurprisingly, within this reality of discrimination and social alienation, a significant number of studies have found that trans people, in comparison to the general population, suffered from lower levels of mental health, psychological wellbeing and quality of life (e.g., Budge, Adelson and Howard, 2013; Dean, Meyer,

\footnotetext{
2 The project "Gender identity law: Impact and challenges of legal innovation in the (trans)gender field" was developed in partnership with Instituto Universitário de Lisboa ISCTE-IUL, ILGA Portugal Organisation - Lesbian, Gay, Bisexual, Trans and Intersex Intervention, and FRI - The Norwegian Organisation for Sexual and Gender Diversity; it was funded by EEA Grants Portugal and sponsored by the Commission for Citizenship and Gender Equality.
} 
Robinson et al., 2000; Newfield, Hart, Dibble and Kohler, 2006; Sánchez and Vilain, 2009). Trans people have been identified as being at greater risk for developing: anxiety disorders (Hepp, Kramer, Schnyder et al., 2005; Mustanski, Garofalo and Emerson, 2010); depression (Nemoto, Bodeker and Iwamoto, 2011; Nuttbrock et al., 2010); social phobia and adjustment disorders (Gómez-Gil, Trilla, Salamero et al., 2009); substance abuse (Lawrence, 2008); or eating disorders (Vocks, Stahn, Loenser and Tegen-bauer, 2009). Concurrently, suicide ideation and attempt rates among this population are very high, with studies suggesting that between $30 \%$ to $40 \%$ of trans people have attempted suicide (e.g., McNeil, Bailey, Ellis and Regan, 2013; Nuttbrock et al., 2010). The numbers are higher if we consider trans youth, with studies indicating that between $50 \%$ to $88 \%$ have considered or attempted suicide (e.g., Israel and Tarver, 1997).

Faced with this alarming scenario, studies have aimed to identify ways to reduce discrimination, stigma and violence, while promoting equality, social integration, enhanced mental health and life satisfaction among this population. Research has shown the positive impact of social transition (McNeil et al., 2013; Pinto and Moleiro, 2015), and the significant improvement on the quality of life and psychological well-being of trans people as correlative to adequate clinical support, including the access to gender affirming procedures such as hormonal and surgical interventions (World Medical Association, 2015; Coleman, Bockting, Botzer et al., 2011; Bränström and Pachankis, 2019; Reardon, 2019). In fact, clinicians, and the support they provide, have a significant impact on the lives of trans people through mental health enhancement. This is all the more true if we consider the importance in guaranteeing access to medical treatments, such as hormone therapy and surgery (Coleman et al., 2012). Gatekeeping can be a challenge for both trans people and health professionals (Bess and Stabb, 2009; Bockting, Robinson, Benner, and Scheltema, 2004). Thus, several authors and studies strongly endorse the need for health practitioners to be competent in the effective support of trans patients, and, therefore, the need for accurate training and knowledge (e.g., Carroll and Gilroy, 2002; Hendricks and Testa, 2012; Israel, Gorcheva, Walther, Sulzne, and Cohen, 2008; Raj, 2002; Pinto and Moleiro, 2015).

Few studies however, have examined the impact of legal gender recognition (LGR), i.e. the access to procedures aimed to change legal sex and name on birth certificates or other official legal documents, on the [mental health, social or psychological wellbeing] of trans people. 


\section{Legal gender recognition and principles of Human Rights}

Legal identification is required for many fundamental activities in daily life, such as applying for jobs, renting accommodation, opening a bank account, or voting. Thus, there are severe risks of marginalisation and discrimination for trans and non-binary people whose documents are incongruent with their gender identity and expression (Open Society Foundations, 2014). The findings from the FRA's study (FRA, 2014, p.11) on the situation of trans people in the EU are clear:

The lack of identity documents that conform with one's gender identity or expression can lead to discrimination. One in three trans respondents felt discriminated against when showing their identification card or other official document that identifies their sex. Almost nine in ten (87\%) say that easier legal procedures for gender recognition in their preferred gender would help them to live a more comfortable life.

However, the vast majority of trans and non-binary people around the world cannot obtain official documents presenting a name and sex which match their gender identity (Open Society Foundations, 2014). Accordingly, LGR has been highlighted as a Human Rights issue (e.g., European Commission, 2012). In the last decade, various countries have created or improved legislation regulating legal sex and name change for trans people on their official documents. Thus, this topic has been addressed as a political and civil rights issue, with specific legal intricacies and a worldwide scope. Activists, politicians (e.g., Hammarberg, 2009), international Human Rights organisations and professional associations, including medical professionals (e.g. Coleman et al., 2011; World Medical Association, 2015) all around the world have been advocating for LGR procedures in compliance with relevant principles of Human Rights.

Different states have been producing varying legislation or jurisprudence on the requirements that allow LGR (Open Society Foundations, 2014). Although proof of genital surgeries tends to be privileged over other evidence, requirements or preconditions may comprise: transition-related medical treatment such as hormonal or gender affirming surgeries; sterilisation, either explicitly or by requiring medical procedures that result in sterilisation; prohibition of current parenting or the lacking intention of having children in the future; living continuously as one's desired gender, 
with gender expression matching gender identity; divorce; or a medical diagnosis (Anders, Caverly, and Johns, 2014; Pinto and Moleiro, 2015). Moreover, an important distinction among LGR procedures is whether they require only administrative dealings or also call for a judicial trial (Open Society Foundations, 2014). In 2012, Argentina was the first country to implement LGR administrative procedures based on the principle of self-determination, this is, the first to legally recognise a person's gender identity without any preconditions or requirements (Boletín Oficial, 2012). The Argentinean law has been described as particularly progressive (UNDP, 2013; Winter, Diamond, Green et al., 2016; Lo and Horton, 2016) and as "a shift in international best practice, based solidly on human rights principles" (Open Society Foundations, 2014, p.10). In recent years, other countries followed in the steps of Argentina, implementing LGR procedures based on the principle of self-determination although some still differ in particular requirements, such as age limits or the enforcement of a mandatory "reflection period".

Accordingly, and since 2017, the World Professional Association for Transgender Health (WPATH, 2017) acknowledges that, for optimal physical and mental health, persons must be able to freely express their gender, whether or not that identity conforms to others' expectations. In parallel, it "urges governments to eliminate barriers to gender recognition, and to institute transparent, affordable and otherwise accessible administrative procedures affirming self-determination". WPATH also advocates that appropriate LGR should be available to trans youth, including those who are under the age of majority, and that choices of identity limited to the gender binary may be inadequate to reflect all gender identities.

As mentioned above, few studies have examined the implementation and impact of LGR legislations. Nevertheless, there is some evidence correlating legal sex change to lower rates of suicide ideation and suicide attempts (Bauer, Scheim, Pyne et al., 2015). Conversely, the inability to access LGR was found a significant predictor for self-rated health (Zeluf, Dhejne, Orre, et al., 2016). A study on the impact of Argentina's LGR law on living conditions, stigma and discrimination experiences of trans women (Arístegui, Radusky, Zalazar et al., 2017) showed positive changes, both in general and in particular domains such as education, health care, work, security, and civil rights. Additionally, a general empowering effect on the community can be inferred after the law's enactment. However, remaining barriers to full implementation were identified. These are both internal and subjective (e.g. age, internalized stigma), and external (e.g. lack of trained professionals and public servants, reluctance to implementation in conservative provinces). 


\section{Trans Rights and Legal Gender Recognition in Portugal}

In Portugal, it was only in 1995 that the National Board of Physicians revoked a ban forbidding sex reassignment surgery that was until then part of its Deontological Code, which was considered unethical and illicit (Hines and Santos, 2018). However, since 1995, a commission of the National Board of Physicians is tasked with approving - or not - each application for gender affirming treatments, after the applicant has undergone two independent clinical assessments. This practice has been systematically criticised by LGBTIQ+ activists and organisations as an undue and excessive gatekeeping procedure. In fact, there is national evidence of clinical practices contrary to international recommendations, including undue gatekeeping, being considered as a significant barrier in accessing gender affirming medical treatments (Pinto and Moleiro, 2012; 2015).

Before 2011, legislation on LGR was non-existent in Portugal. Trans people wishing to change their official documents had to sue the State in a judicial process that could take several years. As a result, only some people were successful since most of the above-mentioned requirements were imposed in court, including proof of sterilisation and childlessness; proof of "completed" hormonal and surgical procedures, including genital surgery; and divorce among others. In September 2010, a Bill was proposed by the government and approved by a majority in the Parliament. Thereafter, the law was vetoed by the President of the Republic, but was reiterated by the same majority in the Parliament, entering into force in March 2011.

Law no.7/2011 established a new administrative process, accessible to people of Portuguese nationality and of legal age ( $>18$ yo). The only requirement was the presentation in a Civil Registry of a document attesting a clinical diagnosis of "gender identity disorder", supported by a sexology team of clinicians comprising of at least one psychiatrist and one clinical psychologist. The process was intended to be expeditious: within 8 days the registrar was required to accept the request, ask for further information, or reject the request (Open Society Foundations, 2014). The law was described by the European Commission as "the first European law on name change and legal gender recognition that meets the Yogyakarta Principles and the Recommendations of the Commissioner for Human Rights of the Council of Europe" (European Commission, 2012, p. 72). 


\section{The Study}

The study at hand forms part of a larger project and referred to as "the first comprehensive study on medical care and gender identity in the Portuguese context" (Hines and Santos, 2017, p.15). Its two main goals were: (1) to assess the implementation and enforcement of Law no.7/2011, describing how the new LGR administrative process was being implemented, while identifying possible difficulties and processes of resistance to legal innovation, and proposing solutions for the eradication of such difficulties; and (2) to explore the impact of LGR on the trans people's private lives, including their psychological well-being and satisfaction with life, as well as on their access to vital spheres of social life, such as access to work, health or education. These goals were contextualised into the analysis of the initial 5 years of the implementation of the law, that is, between 2011 and 2016.

\section{Methods}

This research project employed a mixed-methods, sequential approach (Creswell, 2009; Mason, 2006), making use of both quantitative (online survey) and qualitative (in-depth interviews) methodologies which informed each other. It also employed a multi-informant methodology, which allowed for a greater conceptualisation and comprehensiveness of the obtained results as it permitted the analysis of the convergence and corroboration of results through different strategies and different informants. The use of the results of one methodology informed others, leading to the discovery of paradoxes and contradictions in the results that lead back to a reframing of research issues (Johnson, Onwuegbuzie, and Turner, 2007).

\section{Participants}

For the quantitative online survey, a total of 68 people participated in the study, aged 16 to 60 years old $(M=29 ; \mathrm{SD}=11.11)$. All the participants were of Portuguese nationality and identified themselves as part of the trans and non-binary community. At the time of the study, 62 participants resided in Portugal, 6 were living in other countries. $72 \%$ of participants had been assigned female at birth, $27 \%$ assigned male 
at birth, and only $1 \%$ was assigned as intersex. In terms of self-identification, $13 \%$ identified as women, 37\% identified as men, 13\% identified as transsexual women or trans(gender) women, 15\% identified as transsexual men or trans(gender) men, and the remaining $22 \%$ identified as non-binary or gender fluid. With regard to educational status, most participants (54\%) had completed high school and $22 \%$ had enrolled or completed some college degree. In terms of their professional situation, $32 \%$ of participants were students, less than $30 \%$ had full-time employment and $16 \%$ were unemployed (with the remaining participants reporting studying part-time or other situations). In terms of their social experiences, 59\% of participants indicated that they lived according to their gender identity in all contexts, $34 \%$ of participants reported that they lived according to their gender identity but only in some contexts, and $7 \%$ of participants expressed that they did not live according to their gender identity. Finally, in regard to the legal recognition of their gender identity, 32\% of participants $(n=21)$ had already changed their legal name and gender. Of those, all except 3 had obtained that recognition after the year 2011 through Law no. 7/2011. The remaining $68 \%(n=44)$ had not changed their legal name and gender.

For the qualitative in-depth interviews, three different groups of stakeholders were involved in this project: health professionals $(n=12$; one of which did not complete the interview); trans persons $(n=6)$ and representatives of the major trans or LGBTIQ+ organizations in the country $(n=5)$.

Healthcare professionals were identified through a list provided by the Civil Registry as those qualified and recognised as being able to sign the diagnostic report required by Law no.7/2011. The selected healthcare professionals represented $25 \%$ of the total national registry, composed of 40 to 50 professionals. The 12 healthcare practitioners were selected as to represent a diverse sample in terms of specialties (e.g. clinical psychologists, psychiatrists, endocrinologists, surgeons), distinct health care units in the public $(n=7)$ or private $(=5)$ sectors, and in the major hospitals and services for trans health in the country ( 6 from the north; 2 from the centre; and 4 from the capital; no services exist in the south). Overall, 7 physicians and 5 psychologists were interviewed, out of which 7 identified as women and 5 as men (no health professionals identified as trans, transgender, trans man or trans woman, nor intersex).

As a means to provide a voice and to obtain in-depth information from trans individuals, 6 participants from the online survey who had indicated being available for further contact and participation in the study were contacted. These participants 
included 4 trans women, 1 trans man, and 1 non-binary / transgender person. In this group, 3 participants had not yet obtained the legal recognition of their gender identity, 2 had done it through Law no.7/2011, and 1 had obtained it prior to 2011 through a judicial process. The sampling of these participants was intentional as to best represent a variety of experiences.

Finally, 5 trans or LGBTQI+ association representatives were interviewed (API - Action for Identity; AMPLOS - Association of Mothers and Fathers for Sexual Orientation and Gender Identity Freedom; ILGA Portugal - Lesbian, Gay, Bisexual, Trans and Intersex Intervention; JANO - Support Association for People with Gender Dysphoria; ex aequo - network of LGBTIQ+ youth and supporters).

Instruments and Procedures

A survey was developed for the purpose of the study. It included demographic variables, and a set of open- and closed-ended questions on the processes of diagnosis and clinical care, and experiences of LGR. As it was designed to be dynamic, it presented participants with questions that were generated based on their previous answers. Furthermore, the survey sections presented to each participant depended on the participant's profile type: (a) under 18 (16-17 years old), residing in Portugal; (b) adult, residing in Portugal, who accessed LGR before 2011; (c) adult, residing in Portugal, who accessed LGR through Law no.7/2011; (d) adult, residing in Portugal, without LGR; (e) under 18 (16-17 years old), living abroad; (f) adults, residing abroad, who accessed LGR before 2011; (g) adults, resident abroad, who accessed LGR through Law no.7/2011; and (h) adults, living abroad, without gender identity legal recognition. Depending on the profile assigned to the participant, he/she/they would be forwarded to a specific section of the questionnaire; hence, the participants did not respond to all questions. For instance, participants aged 16 and 17 were not asked about the impact of LGR as it was not possible, at the time, to legally change one's name or gender before the age of 18. Another example was the case of participants residing abroad, for whom questions regarding access to consulates and procedural issues were inquired, as well as on the process of obtaining a diagnostic report in other countries.

The survey also included the Satisfaction with Life Scale (Diener, Emmons, Larsen and Griffin, 1985), with 5 items answered on a Likert scale. This scale has been 
validated for the Portuguese population (Simões, 1992), and presents adequate values of consistency and reliability $(\alpha=.89)$. The scale was complemented with additional questions regarding the positive/negative impact that legal gender recognition had on participants' lives (i.e. the impact that the change of name and legal sex had in their private life, their happiness, and social integration/professional aspects). Results from the online survey were analysed with the IBM SPSS Statistical Software (for descriptive statistics and group mean differences).

As for the in-depth interviews, a specific interview guide was developed for each participant typology. All interviews were conducted by a team-member of the project. Although most of the interviews were conducted in person, some were performed via Skype - due to the geographical dispersion of the participants. The duration of interviews ranged from 30 to 90 minutes. Interviews were transcribed verbatim, and text was examined using thematic analysis - a method for identifying, analyzing, and reporting patterns (themes) within data (Braun and Clark, 2006). Domains or main thematic categories were derived from the goals of the study and the blocks of interview questions; however, categories were derived bottom up, that is, they emerged from the data. Thus, the final analysis resulted from a blended model. A team of two researchers and two research assistants made decisions on the data by consensus, following Consensual Qualitative Analysis (Hill, Knox and Thompson, 2005). Consensus on all units of analysis and categorisation was achieved through discussion. The senior researcher also acted as an auditor, facilitating the discussion when discrepancies arose. Final units of analysis and categories were checked against the raw data (Hill et al., 2005). Interview excerpts were selected for illustration of each main category.

In both components of the project (online survey and interview), adequate informed consent was obtained, clarifying the volunteer nature of participation, and anonymity and confidentiality of responses. Issues of privacy and personal data were of particular importance in the case of Trans participants. Representatives of NGO's, for the most part, presented their official and public positions regarding the subject.

\section{Results}

Relevance and impact of LGR on trans people's psychological and social well-being 
The vast majority of the participants in the survey (91\%) described Law no.7/2011 as "important" or "extremely important". In parallel, all health practitioners but one, and all the LGBTIQ+ associations emphasised the relevance of the new law, highlighting the importance of the new administrative character of LGR.

Data on the Satisfaction with Life Scale (Sniezek et al., 2010) revealed that the participants who had already accessed LGR evaluated their satisfaction with life with statistically higher values than those that had not (mean total sample: $\mathrm{M}=4.53, \mathrm{SD}=1.37$ on a scale 1-7; mean of those with legal recognition of gender identity: $M=5.03$; $\mathrm{SD}=1.18$; mean of those without legal recognition of gender identity: $\mathrm{M}=4.14, \mathrm{SD}=1.40$; $t(47)=2.26, p=0.028$ ). Additionally, survey participants who had already changed their name and legal gender, before or after 2011, were asked how this change impacted their lives (positive or negative) in several dimensions of psychological and social well-being. Table 1 shows the results. Regarding psychological well-being, all participants reported a positive impact; thus $88.2 \%$ of participants reported that LGR had a "very positive" impact in their psychological well-being, and the remaining $11.8 \%$ reported that the impact was "positive." Regarding happiness, $76.5 \%$ of participants reported that LGR had a "very positive" impact on happiness, while the other $23.5 \%$ reported that the impact was "positive." In terms of their family life, $35.3 \%$ of participants reported that LGR had a "very positive" impact; 35.3\% of respondents indicated that the impact was "positive", and $23.5 \%$ of participants reported the impact "was neither positive nor negative". Regarding the sphere of marriage and love life, $58.8 \%$ of participants reported that LGR had a "very positive" impact; $11.8 \%$ indicated that the impact was "positive", and $17.6 \%$ of respondents indicated that the impact was "neither positive nor negative". Concerning the access to employment or maintaining jobs, $52.9 \%$ of participants reported that LGR had a "very positive" impact; $23.5 \%$ of participants indicated that the impact was "positive", $5.9 \%$ of the participants reported that the impact was "neither positive nor negative", and $5.9 \%$ of participants indicated that LGR had a "negative" impact on access to work or in preserving jobs. Regarding the educational and academic sphere, $41.2 \%$ of participants indicated LGR had a "very positive" impact, 5.9\% of the participants reported that the impact was "positive", and $23.5 \%$ of participants indicated that the impact was "neither positive nor negative". Concerning the access to public services, which includes the access to health services, $47.1 \%$ of participants reported a "very positive" impact of LGR and $41.2 \%$ of participants reported that the impact was "positive". Concerning to the scope of security in public environments, $58.8 \%$ of participants indicated that LGR had a "very positive" impact and $29.4 \%$ of participants 
indicated that the impact was "positive". In relation to overall social well-being, all participants indicate that LGR had a positive impact, namely $82.4 \%$ report that the impact was "very positive" and $17.6 \%$ of respondents indicated that the impact was "positive".

Table 1: Impact of Legal Gender Recognition on psychological and social wellbeing

\begin{tabular}{|c|c|c|c|c|c|c|c|c|c|c|c|c|}
\hline & \multicolumn{2}{|c|}{$\begin{array}{l}\text { Very } \\
\text { positive }\end{array}$} & \multicolumn{2}{|c|}{ Positive } & \multicolumn{2}{|c|}{$\begin{array}{l}\text { Neither } \\
\text { positive } \\
\text { nor } \\
\text { negative }\end{array}$} & \multicolumn{2}{|c|}{ Negaive } & \multicolumn{2}{|c|}{$\begin{array}{l}\text { Very } \\
\text { negative }\end{array}$} & \multicolumn{2}{|c|}{$\begin{array}{l}\text { Not } \\
\text { applicable }\end{array}$} \\
\hline & $n$ & $\%$ & $n$ & $\%$ & $n$ & $\%$ & $n$ & $\%$ & $n$ & $\%$ & $n$ & $\%$ \\
\hline $\begin{array}{l}\text { Psychological } \\
\text { well-being }\end{array}$ & 15 & 88.2 & 2 & 11.8 & - & - & - & - & - & - & - & - \\
\hline Happiness & 13 & 76.5 & 4 & 23.5 & - & - & - & - & - & - & - & - \\
\hline Family life & 6 & 35.3 & 6 & 35.3 & 4 & 23.5 & 1 & 5.9 & - & - & - & - \\
\hline $\begin{array}{l}\text { Marriage or } \\
\text { love life }\end{array}$ & 10 & 58.8 & 2 & 11.8 & 3 & 17.6 & - & - & - & - & 2 & 11.8 \\
\hline Employment & 9 & 52.8 & 4 & 23.5 & 1 & 5.9 & 1 & 5.9 & - & - & 2 & 11.8 \\
\hline $\begin{array}{l}\text { Education } \\
\text { and academic } \\
\text { life }\end{array}$ & 7 & 41.2 & 1 & 5.9 & 4 & 23.5 & - & - & - & - & 5 & 29.4 \\
\hline $\begin{array}{l}\text { Access to } \\
\text { public } \\
\text { services }\end{array}$ & 8 & 47.1 & 7 & 41.2 & 1 & 5.9 & - & - & - & - & 1 & 5.9 \\
\hline $\begin{array}{l}\text { Security in } \\
\text { public } \\
\text { environments }\end{array}$ & 10 & 58.8 & 5 & 29.4 & - & - & - & - & - & - & 2 & 11.8 \\
\hline $\begin{array}{l}\text { Overall social } \\
\text { well-being }\end{array}$ & 14 & 82.4 & 3 & 17.6 & - & - & - & - & - & - & - & - \\
\hline
\end{tabular}


Results from the qualitative data support these numbers. All the health practitioners but one, as well as all the LGBTIQ+ associations described the positive impact of new law on trans people's psychological well-being and social integration. The following excerpts of interviews and answers to open-ended questions on the survey illustrate the relevance and positive impact of LGR as demonstrated above.

"It's a feeling of freedom to finally have the recognition achievement of my identity, coupled with the pleasant feeling that I don't have to go through embarrassments every time I use services where it is necessary to present a legal document." [Trans man, 26 yo]

“There are many situations in which people did not perceive me as a girl. [But] it's very different [now] I have a document that protects me as such. For example, something as simple as going to the bathroom. If I currently get myself into any trouble [...], the changed document is already different." [Trans woman, 29 yo]

"I no longer suffer from anxiety whenever I have to present a document. In college I started to be treated by my name by all teachers and stopped having to sign reviews and work sheets with the birth name, which was a relief. "[Trans man, 24 yo].

"The first impact is the obvious happiness and well-being. Even self-esteem. The name given at birth was a "reminder" of what I was not. A "legal confirmation" to others that I am not like them. After the change, all the awkwardness and embarrassment ended regarding the name, particularly in the context of school and access to services." [Trans man, 19 yo]

Implementation of Law no.7/2011 by the Institute of Registries and Notaries

During the first months after the new law entered into force, the Institute of Registries and Notaries (IRN) expressed a need for guidance on what the clinical report should include as mentioned in Law no.7/2011, and on how to identify which professionals would be apt to sign them (i.e., which professionals integrate a "multidisciplinary clinical team of clinical sexology"). The IRN developed its own model for the 
diagnosis report and, together with the National Board of Physicians, a list of health practitioners qualified to sign them (which included doctors and psychologists). The data collected showed that the development of this list was based mainly on informal knowledge about health practitioners working with trans people in Portugal, both in the National Health Service and in private practice. However, the findings show that the list included health professionals who no longer work and/or who have never worked meaningfully in the field. In parallel, a large number of professionals reported not knowing the criteria underlying the development and possible updates of the list, and warned about the non-inclusion of colleagues who work in their teams. Nevertheless, various health professionals indicated that this list carries some advantages notably referring to the supposed guarantee of a competent healthcare provision to trans people, as it would indicate a number of health professionals who would have appropriate training and experience in this field. However, all LGBTIQ+ associations, various health practitioners and trans participants questioned the very existence of this list and its legitimacy within the spirit of Law no.7/2011. Additional problems resulting from the existence of this list were also reported, including cases in which LGR was rejected in civil registry offices because the report presented was not signed by any of the professionals on the list.

Health practitioners as gatekeepers in $L G R$

Since the new law included a diagnosis requirement, it formally transferred the LGR gatekeeping function from judges to health practitioners. The results showed that different health professionals performed this function in different ways. Some showed a distinction in the clinical processes related to the access to gender affirming treatments from the clinical evaluation procedures to access LGR. However, a proportion of cases have demonstrated a clear overlap between the clinical and legal spheres. First, some health professionals demanded two clinical assessments be made by independent teams before signing the report. Second, some practitioners indicated that they only sign the reports when other criteria that extend beyond the diagnosis itself (such as the beginning of hormonal treatments, or "real life experience") are fulfilled. Finally, the results also showed that some professionals supported the diagnosis on their own personal views and gender biases, including their normative expectations of gender expressions (i.e., evaluating trans people as "true or false transsexuals"). 
The number of clinical appointments (and, consequently, the time required to obtain the report attesting the diagnosis) was variable: some trans people obtain the report in only one appointment, while others indicated that they had more than 15 appointments before having the report (with some participants indicating that the process lasted more than 3 years). In parallel, some reported that, although they had already started hormonal therapy and/or are socially living in accordance with their gender identity, they were still in the process of obtaining the report attesting the diagnosis in order to access LGR.

The results also revealed the difficulties that Portuguese people living abroad had in accessing the new law. This was due to the fact that the reports signed by foreign health professionals were not being accepted at civil registry offices - because these professionals were not in the IRN list of "health professionals qualified to sign reports"; and that external representation offices (consulates and embassies) were not informed about the law and its procedures.

All interviewed LGBTIQ+ associations claimed that the Portuguese law should evolve in order to exclude the diagnosis requirement and guarantee the right to selfdetermination. Half of the health professionals interviewed $(n=6)$ were in favour of this development and $53 \%$ of the trans participants supported self-determination (19\% answered "I do not know" to this question).

Age limit and gender binarism in Law no.7/2011

A vast majority $(87 \%)$ of trans participants argued in favour of changing the law in order to allow minors' access to LGR. All interviewed LGBTIQ+ associations argued similarly. A significant group of health professionals $(n=5)$ also advocated for this change, highlighting the age of 16 as a possible reference and describing cases of trans youth who already live according to their identity and have started hormonal therapy. Seven trans participants who answered the survey were 16 or 17 years old: two already lived, in all contexts, according their identity and five in just some contexts (for example, within the family, groups of friends or school environment); three had started hormonal treatment; and two reported concrete difficulties in contexts which require the presentation of documents as the Portuguese Citizen Card. As a trans participant described: 
"When a person reaches the age of 18 years, they are likely to have been through humiliating enough situations that will leave a mark for the rest of their lives and that could have been avoided if they had the possibility to access LGR." [Trans man, 24yo]

Additionally, Law no.7/2011 did not legally recognise identities of people who identified themselves outside the female/male binary categories. Fifteen of the 68 participants in the survey identified themselves as transgender/non-binary; and of these, 3 said they did not access Law no.7/211 because it did not provide for legal recognition of their identities. All interviewed LGBTIQ+ associations warned against this restriction and 6 healthcare professionals reported finding advantages associated with the possibility of a gender-neutral legal marker.

\section{Discussion}

The lack of legal gender recognition for transgender people triggers situations of social inequality. In recent years, different States have proposed different solutions to overcome this inequality. In 2011, Portugal passed a law that was considered the first law of legal gender recognition that meets the standards of relevant Human Rights principles and was pointed out as innovative in the European context. The present project constituted the first formal evaluation of the Portuguese "gender identity law". The project aims were (i) to assess the implementation and enforcement of Law N.97/2011; and, more importantly, (ii) to understand the impact of the law on the social and psychological well-being of transgender people, including on transgender people's access to vital spheres of social life.

The results of our study align with the conclusions from the still scarce research on the psychological and social impact of LGR (Arístegui et al., 2017; Bauer et al., 2015; Zeluf et al., 2016), showing meaningful improvements in the psychological and social well-being of those accessing LGR. Satisfaction with life shows to be significantly different between trans persons who had accessed to the legal recognition of their gender identity and those who had not been able to do so. In addition and overall, the impact of the law was generally perceived by trans people as "very positive" or "positive" in an array of domains: psychological well-being, family life, intimate relationships, employment, education/academic life, access to public places and services, perceived safety in public environments, and overall social well-being. A key 
aspect may be highlighted, namely the choice of the timing of filling the legal recognition papers, as the moment may also be relevant for promotion of protective factors or, alternatively, exacerbation of risk factors (e.g. in the family or work contexts). In light of this, providing for each person to have recourse to LGR in his/her/their own time would seem to allow individuals to prepare family members (such as spouses and/or children) and work/educational stakeholders (e.g. choosing a period of work vacations or a transition from high school to college setting). Obstacles to this free choice include the requirements for court proceedings (prior to 2011), or demonstration of diverse requisites and undue clinical gatekeeping (Anders, Caverly, and Johns, 2014; Pinto and Moleiro, 2012, 2015).

Indeed, our findings revealed that some health professionals demanded that two clinical assessments were made by independent teams before signing the report (as mentioned before, two independent clinical assessments are a common practice in Portugal to access gender affirming surgeries, but are not a requirement established by Law $\mathrm{n}^{\mathrm{0}}$ /2011). This and other procedures (such as the creation of a limited list of qualified clinicians allowed to sign the reports) were identified as resistances to legal innovation (Castro, 2012; Castro and Batel, 2008). Such resistance comes from the fact that action and speech may be disconnected, and this is especially important for the creation of new laws, as many are formulated through vague and general terms identifying the desired goals and values to be respected, but not necessarily setting out in detail the actions to be taken (Castro, 2012). Therefore, recommendations for further legislative measures in this domain include the provision of specific guidelines for implementation, beyond desired goals and values. For instance, special concerns should be addressed with regard to the overlap between the legal sphere (legal recognition of gender identity) and clinical sphere (e.g. trans-affirmative health care), as well as measures to be taken in educational contexts (e.g. support to children and youth and their families; requirements in schools and universities for gender-diverse population).

Some issues were identified as noteworthy aspects still missing in the new law, including the facts that children's and youth's access to social and/or legal recognition of gender identity were not included, and the relatively lacking mention of non-binary and gender fluid individuals. Thus, the multiple experiences and heterogeneous diversity of all individuals who identify as trans and/or outside of the male/female binary was still not addressed in the law of 2011, and recommendations resulted into highlighting this gap. 
Although a mixed-methods approach and a multi-informant methodology were employed, our study has its own limitations, particularly regarding the sample size. We recommend future research to reach larger samples of trans and non-binary people, and to compare different legal contexts, including those with requirements and preconditions to access LGR. Nevertheless, the results and recommendations of this research became an important piece of advocacy in the process of changing the law in Portugal. As experts, among other health professionals and social scientists, the authors were heard in Parliament to respond to questions by all political parties on the results of this study and to provide scientifically-informed opinions on the revision of the law, including self-determination. In fact, a new law relating to LGR (Law no.38/2018) entered into force in 2018, recognizing the right to self-determination of trans people over 16 years old, granting legal protection of gender identity and expression, and establishing the right to body integrity for intersex babies and children.

\section{References}

Anders, S., Caverly, N. and Johns, M. (2014). Newborn bio/logics and US legal requirements for changing gender/sex designations on state identity documents. Feminism and Psychology, 24(2), 172-192.

Arístegui, I., Radusky, P. D., Zalazar, V., Romero, M., Schwartz, J. and Sued, O. (2017). Impact of the Gender Identity Law in Argentinean transgender women. International Journal of Transgenderism, 18(4), 446-456.

Bauer, G.R., Scheim, A. I, Pyne, J., Travers, R. and Hammond, R. (2015). Intervenable factors associated with suicide risk in transgender persons: A respondent driven sampling study in Ontario, Canada. BMC Public Health, 15, 525.

Bess, J. A. and Stabb, S. D. (2009). The experiences of transgendered persons in psychotherapy: Voices and recommendations. Journal of Mental Health Counseling, 31, 265-282.

Bockting, W., Robinson, B., Benner, A. and Scheltema, K. (2004). Patient satisfaction with transgender health services. Journal of Sex and Marital Therapy, 30, 277-294.

Boletín Oficial de la República Argentina. (2012). Ley de Identidade de Género. Año CXX, Nro 32.404. Available at: http://www1.hcdn.gov.ar/BO/boletin12/2012-05/BO24-052012leg.pdf 
Bränström; R. and Pachankis, J.E. (2019). Reduction in mental health treatment utilization among Transgender individuals after gender-affirming surgeries: A total population study. American Journal of Psychiatry, 0, 0-0.

Braun, V. and Clarke, V. (2006). Using thematic analysis in psychology. Qualitative Research in Psychology, 3, 77-101.

Budge, S. L., Adelson, J. L. and Howard, K. A. (2013). Anxiety and depression in transgender individuals: The roles of transition status, loss, social support, and coping. Journal of Consulting and Clinical Psychology, 81(3), 545-57.

Carroll, L. and Gilroy, P. J. (2002). Transgender issues in counselor preparation. Counselor Education and Supervision, 41, 233-242.

Castro, P. (2012). Legal Innovation for Social Change: Exploring Change and Resistance to Different Types of Sustainability Laws, 33(1), 105-121.

Castro, P. and Batel, S. (2008). Social representation, change and resistance: On the difficulties of generalizing new norms. Culture and Psychology, 14, 477-499.

Coleman, E., Bockting, W., Botzer, M., Cohen-Kettenis, P., DeCuypere, G., Feldman, J., ... Adler, R. K. (2011). Standards of care for the health of transsexual, transgender, and gender nonconforming people, 7 th version. International Journal of Transgenderism, 13, 165-232.

Creswell, J. W. (2009). Chapter Ten: Mixed Methods Procedures. In Research Design: Qualitative, Quantitative and Mixed Methods Approaches (pp. 203-224). California: SAGE Publications.

Dean, L., Meyer, I. H., Robinson, K., Sell, R. L., Sember, R., Silenzio, V. M. B., et al (2000). Lesbian, gay, bissexual and transgender health: Findings and concerns. Journal of the Gay and Lesbian Medical Association, 4, 102-151.

Diener, E., Emmons, R., Larsen, R. and Griffin, S. (1985). The satisfaction with life scale. Journal of Personality Assessment, 49, 1105-1117.

European Commission (2012). Trans and intersex people: Discrimination on the grounds of sex, gender identity and gender expression. Luxembourg: European Commission. Available at: http://www.coe.int/t/dg4/lgbt/Source/trans and intersex people EC EN.pdf

FRA - European Union Agency for Fundamental Rights (2014). Being Trans in the European Union: Comparative analysis of EU LGBT survey data. Luxembourg: European Union Agency for Fundamental Rights. 
Gómez-Gil, E., Trilla, A., Salamero, M., Godás, T., and Valdés, M. (2009). Sociodemographic, clinical, and psychiatric characteristics of transsexuals from Spain. Archives of Sexual Behavior, 38(3), 378-92.

Hammarberg, T. (2009). Gender identity and human rights: Issue paper. Strasbourg: Council of Europe.

Hendricks, M. L., and Testa, R. J. (2012). A conceptual framework for clinical work with transgender and gender nonconforming clients: An adaptation of the minority stress model. Professional Psychology: Research and Practice, 43, 460-467. doi:10.1037/a0029597

Hepp, U., Kraemer, B., Schynder, U., Miller, N. and Delsignore, A. (2005). Psychiatric comorbidity in gender identity disorder. Journal of Psychosomatic Research, 58, 259-261.

Hill, C., Knox, S., Thompson, B. J., Williams, E. N., Hess, S. A. and Ladany, N. (2005). Consensual qualitative research: an update, Journal of Counseling Psychology, 52(2), 196205.

Hines, S. (2007). Transforming gender: Transgender practices of identity, intimacy and care. Bristol: Policy Press.

Hines, S. and Santos, A. C. (2018). Trans* policy, politics and research: The UK and Portugal. Critical Social Policy, 38(1), 35-56.

Israel, T., Gorcheva, R., Walther, W. A., Sulzne, J. M. and Cohen, J. (2008). Therapists' helpful and unhelpful situations with LGBT clients: An exploratory study. Professional Psychology: Research and Practice, 39, 361-368.

Israel, G. E. and Tarver, D. E. (1997). Transgender care: Recommended guidelines, practical information and personal accounts. Philadelphia, PA: Temple.

James, S. E., Herman, J. L., Rankin, S., Keisling, M., Mottet, L. and Anafi, M. (2016). The Report of the 2015 U.S. Transgender Survey. Washington, DC: National Center for Transgender Equality.

Johnson, R., Onwuegbuzie, A. and Turner, L. (2007). Toward a definition of mixed methods research. Journal of Mixed Methods Research, 1(2), 112-133.

Kenagy, G. P. (2005). Transgender health: findings from two assessment studies in Philadelphia. Health Social Work, 30(1), 12-26.

Lawrence, A. A. (2008). Gender identity disorders in adults: Diagnosis and treatment. In D. L. Rowland and L. Incrocci (Eds.), Handbook of sexual and gender identity disorders (pp. 423-456). New York: Wiley. 
Lo, S. and Horton, R. (2016). Transgender health: An opportunity for global health equity. Lancet, 388(10042), 316-318.

Lombardi, E. L.,Wilchins, R. A., Priesing, D. and Malouf, D. (2001). Gender violence: Transgender experiences with violence and discrimination. Journal of Homosexuality,42(1), 89-101.

Mason, J. (2006). Six strategies for mixing methods and linking data in social science research. National Centre for Research Methods. Working Paper Series, (04/06).

McNeil, J., Bailey, L., Ellis, S. and Regan, M. (2013). Speaking from the Margins: Trans Mental Health and Wellbeing in Ireland. Transgender Equality Network Ireland (TENI). Available at: $\quad$ https://lgbt.ie/wpcontent/uploads/2018/06/attachment 5bdd0cd5-16b6-4ab6-9ee6-a693b37fdbcf.pdf

Mustanski, B. S., Garofalo, R. and Emerson, E. M. (2010). Mental Health Disorders, Psychological Distress, and Suicidality in a Diverse Sample of Lesbian, Gay, Bisexual, and Transgender Youths. American Journal of Public Health, 100(12), 2426-2432.

Nemoto, T., Bodeker, B. and Iwamoto, M. (2011). Social support, exposure to violence, and transphobia: Correlates of depression among male-to-female transgender women with a history of sex work. American Journal of Public Health, 10, 1980-1988.

Newfield, E., Hart, S. Dibble, S. and Kohler, L. (2006). Female-to-male transgender quality of life. Quality of Life Research, 15, 1447-1457.

Nuttbrock, L., Hwahng, S., Bockting, W., Rosenblum, A., Mason, M., Macri, M. and Becker, J. (2010). Psychiatric impact of gender-related abuse across the life course of male-to-female transgender persons. Journal of Sex Research, 47(1), 12-23.

Open Society Foundations (2014). License to be yourself: Laws and advocacy for legal gender recognition of trans people. New York: Open Society Foundation. Available at: http://www.opensocietyfoundations.org/reports/license-be-yourself

Pinto, N. and Moleiro, C. (2012). Experiences of Health Care by Transexual People in Portugal: The perspectives of health professionals and health care users. PSICOLOGIA, 26(1), 129-151.

Pinto, N. and Moleiro, C. (2015). Gender trajectories: Transsexual people coming to terms with their gender identities. Professional Psychology: Research and Practice, 46(1), 12-20.

Pitts, M. K., Couch, M., Mulcare, H., Croy, S. and Mitchell, A. (2009). Transgender People in Australia and New Zealand: Health, Well-being and Access to Health Services. Feminism and Psychology 19(4), 475-495. 
Raj, R. (2002). Towards a transpositive therapeutic model: Developing clinical sensitivity and cultural competence in the effective support of transsexual and transgendered clients. The International Journal of Transgenderism, 6. Available at: http://www.symposion.com/ijt/ijtvo06no02_04.htm

Reardon, S. (2019). The largest study involving transgender people is providing longsought insights about their health. Nature, 568(7753), 446-449.

Rotondi, N. K., Bauer, G. R., Scanlon, K., Kaay, M., Travers, R. and Travers, A. (2011). Prevalence of and Risk and Protective Factors for Depression in Female-to-Male Transgender Ontarians: Trans PULSE Project. Canadian Journal of Community Mental Health, 30(2), 135-155.

Sánchez, F. J., and Vilain, E. (2009) Collective self-esteem as a coping resource for maleto-female transsexuals. Journal of Counseling Psychology, 56(1), 202--209.

Simões, A. (1992). Ulterior validação de uma escala de satisfação com a vida (SWLS). Revista Portuguesa de Pedagogia, XXVI, 3, 503-515.

United Nations Development Programme. (2013). Discussion paper: Transgender health and human rights. New York, NY: UNDP.

Vocks, S., Stahn, C., Loenser, L. and Tegenbauer, U. (2009). Eating and body image disturbances in male-to-female and female-to-male transsexuals. Archives of Sexual Behavior, 38(3), 364-377.

Winter, S., Diamond, M., Green, J., Karasic, D., Reed, T., Whittle, S. and Wylie, K. (2016). Transgender people: Health at the margins of society. The Lancet, 388(10042), 390-400.

World Medical Association (2015). WMA Statement on Transgender People. Russia, Moscow: World Medical Association. Available at: www.wma.net/policiespost/wma-statement-on-transgender-people/

World Professional Association for Transgender Health (2017). WPATH Identity Recognition Statement. Available at: www.wpath.org/media/cms/Documents/Web\%20Transfer/Policies/WPATH\%20Iden tity\%20Recognition\%20Statement\%2011.15.17.pdf

Zeluf, G., Dhejne, C. and Orre, C. (2018). Targeted Victimization and Suicidality Among Trans People: A Web-Based Survey. LGBT Health, 5(3), 180-190. 